\title{
Distances between Vehicles in Traffic Flow and the Probability of Collision with Animals
}

\author{
J. Martolos* \\ EDIP s.r.o., Plzen̆, Czech Republic \\ *Coresponding autor: martolos@edip.cz \\ P. Anděl \\ Evernia s.r.o., Liberec, Czech Republic
}

DOI: $10.2478 / \mathrm{v} 10158-012-0036-\mathrm{X}$

\begin{abstract}
This article describes a model used to establish the probability of a collision between a vehicle and animals on roads. Analysis of data obtained from measurements provided by automatic radar enabled us to find general relationships which determine the distribution of time gaps between vehicles in traffic flow. These results were applied (with other applications) to assessments of the impact of traffic on wildlife. These simplified models have demonstrated the road barrier effect, with a certain traffic intensity, on the wildlife.
\end{abstract}

KEY WORDS: Traffic flow gaps, collision probability, animal, vehicle, traffic, intensity.

\section{INTRODUCTION}

The so-called barrier effect of roads, which is associated with the mortality level of animals, depends on a wide range of factors, which may themselves be divided into factors/elements relevant to animals and factors relevant to the road itself. Factors relevant to animals include the following:

- Ethology of the relevant species resulting in basic behavioural patterns;

- Migratory pressures resulting from food or population issues and relationships;

- Character of ecosystems present in the evaluated location.

Factors relevant to roads include the following:

- Type of road and applicable technical solutions;

- Directional and altitude (vertical) structure in the relevant location;

- Traffic intensity.

Therefore, the probability of a collision between a vehicle and an animal also depends (besides other factors) on the traffic intensity occurring on the particular road and on the distances (gaps) between individual vehicles.

\section{DISTANCES BETWEEN VEHICLES IN TRAFFIC FLOW}

Traffic flow is a sequence of vehicles moving in one (or more) lanes in one direction. 
The basic characteristics of traffic flow are:

- Volume of traffic (expressed in number of vehicles per certain time interval - hour, day);

- Speed (average, immediate ...);

- Density (number of vehicles present on a particular section of the road and at a particular time);

- Time gap;

- Distance.

A distance or gap between vehicles may be defined as follows:

- Time gap between vehicles - time between two fronts of passing vehicles travelling one after another in one traffic lane;

- Distance between vehicles - distance between two fronts of passing vehicles travelling one after another in one traffic lane;

- Gap between vehicles - time between the front of a vehicle and the rear of a vehicle travelling one after another or between two oncoming vehicles.

The defined distances and the gaps are used for the following:

- Inclusion of other vehicles into the traffic flow - this is used for example at intersections - the theory defining distances between vehicles at intersections is used to determine the actual capacity of a particular intersection;

- Pedestrian crossings - pedestrians use sufficiently long distances to cross roads;

- Animal road crossings - similarly as for a person, a road represents a barrier for animals (we will focus on this issue in the second section of this article).

\section{POISSON'S DISTRIBUTION OF PROBABILITIES}

The traffic flow theory describes the division of time gaps between vehicles in various ways. Analytical or stochastic (random) models may be used based on direct traffic flow measurements. As far as stochastic models are concerned, probabilistic models are used more frequently, such as Poisson's model, negative-exponential model, etc.

The most suitable model used for the description of the existence of individual gaps/distances between vehicles in accordance with the results of previous and similar measurements (Pistulka, 1970) is Poisson's division method.

Poisson model requirements of use (the so-called Adams-Kinzer criteria):

- Vehicles in traffic flow maintain various distances between them. These distances depend on the density and on the speed of the traffic flow;

- All vehicles may move freely and do not interact with each other. Overtaking is always allowed (corresponds with A traffic quality class);

- Passage of a vehicle through the monitored section of the road is random;

- The probability of the existence of a certain distance between vehicles at the specified time interval is (approximately) equal to the length of the interval.

Although the actual division of distances do not precisely correspond to the theoretical Poisson's distribution, for our purposes (application used to calculate the probability of a collision with an animal) it is sufficient (animals do not behave exactly according to formulas either).

Note: However, we will show that this type of model is precise. Larger deviation was recorded at locations where the traffic flow was affected, i.e. by an intersection nearby 
(mostly with traffic lights), or by a long section of the road without any possibility to overtake.

Let us monitor a random phenomenon: "In a distance $t$ we will find $x$ vehicles".

Poisson's division with random value $\mathrm{X}$ represents the following formula:

$$
P(X)=e^{-\lambda} \cdot \frac{\lambda^{X}}{X !}
$$

$\lambda>0$ is the only parameter of these division. If we know this parameter, then the Poisson's division is firmly established.

The mean value of a random variable is for $\mu=\lambda$ and distribution (dissipation) $\sigma^{2}=\lambda$. Then we have a traffic flow with intensity I (vehicles/hour). Therefore, during the time interval t (s) an average of $\frac{I}{3600} t$ vehicles will pass through the specified section of the road.

Note: the value 3600 in the denominator represents the number of seconds in one hour. Due to the fact that the parameter $\lambda$ represents the average number of vehicles passing through a particular section of the road and during the time interval $t$, the following statement is true:

$$
\lambda=\frac{I}{3600} t
$$

If we do not expect the occurrence of a vehicle within the interval $(\mathrm{x}=0)$, but we are looking for the occurrence of a certain distance (or rather longer than t seconds), the probability (1) has the following form:

$$
P(X=0)=e^{-\lambda}
$$

This changes the original discrete probabilistic division to a continuous division (negativeexponential) - the time gap is also a continuous phenomenon.

Example: A road with traffic intensity I=360 vehicles / hour

$$
\lambda=\frac{360}{3600} t=\frac{t}{10}
$$

Then the distribution probability function of the distance occurrence is $P(t)=e^{-\frac{t}{10}}$.

And the probability of the occurrence of a gap longer than 10 seconds is

$$
P(10)=e^{-\frac{10}{10}}=0,37=37 \%
$$




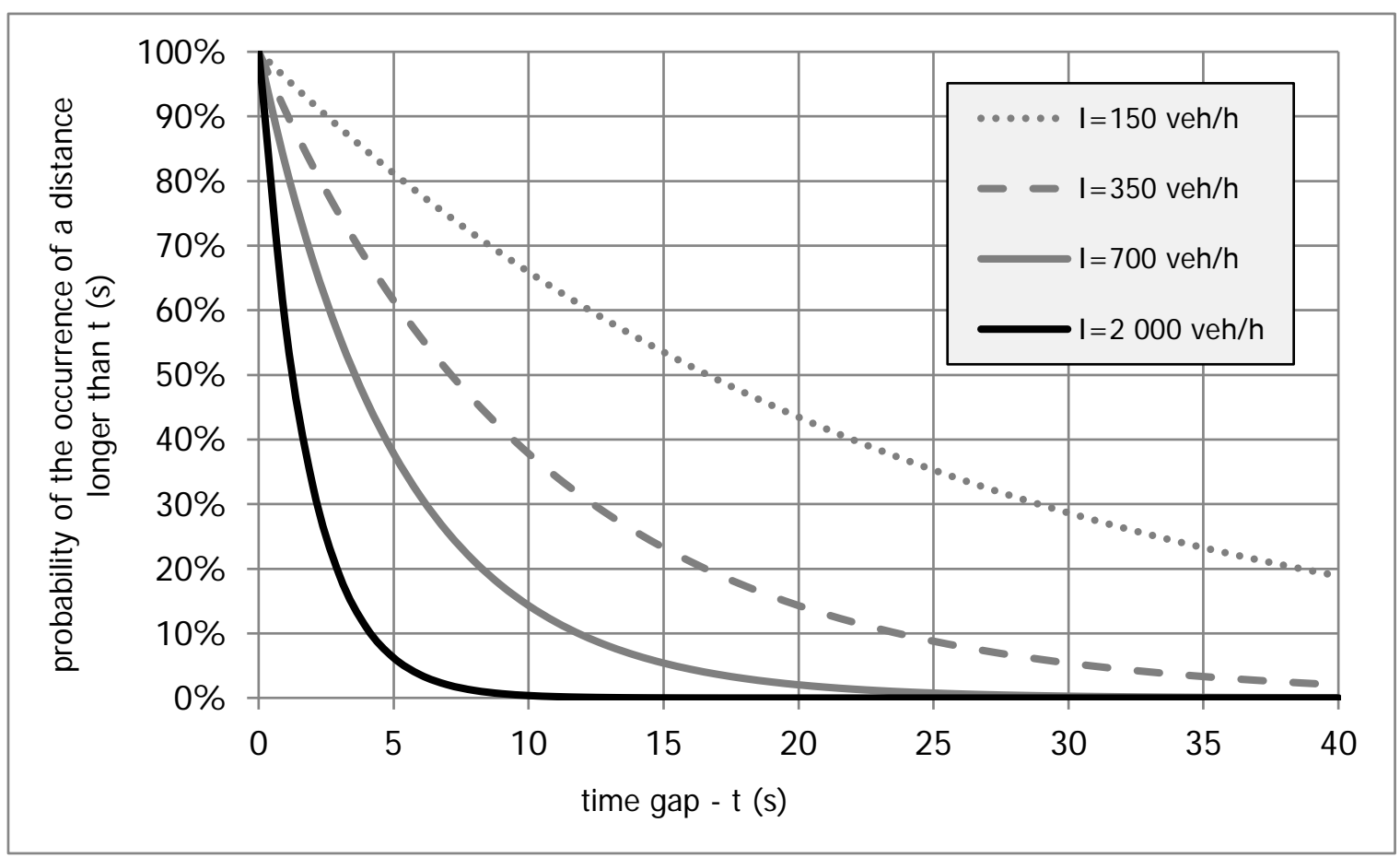

Figure 1: The occurrence of time gaps in various traffic intensities.

Figure 1 shows distribution functions of distance occurrences (i.e. the probability of the occurrence of a longer gap than the given time) for different traffic intensities.

\section{TRAFFIC SURVEYS}

For the purpose of a detailed analysis of gaps / distances, the necessary measurements were performed. An automatic detector (radar) was used, which allowed us to record the exact times of passing vehicles and determine the distances between vehicles. Each week the radar was used at 19 stations on 2nd and 3rd road classes and on local roads. At each station a radar measured continuously for 1 week. Radar records the passage of every vehicle and measures: passage of time, the length of the vehicle, vehicle speed, direction and spacing for the previous vehicle.

The list of stations, time and period of measurements and estimates of average daily intensities (RPDI) (in vehicles per day) are shown in Table 1.

Table 1: List of stations used during the analysis (MK - local road).

\begin{tabular}{|c|l|c|c|}
\hline No & \multicolumn{1}{|c|}{ Station } & Rod & $\begin{array}{c}\text { Estimation } \\
\text { AADT }\end{array}$ \\
\hline 1. & Rokycany & $\mathrm{II} / 183$ & 2527 \\
\hline 2. & Holoubkov & $\mathrm{II} / 2341$ & 439 \\
\hline 3. & Dobřany & $\mathrm{I} / 180$ & 4157 \\
\hline 4. & Aš & $\mathrm{I} / 216$ & 5730 \\
\hline 5. & Zbůch & $\mathrm{I} / 26$ & 8671 \\
\hline 6. & Mirošov & $\mathrm{II} / 117$ & 793 \\
\hline 7. & Třemošná & $\mathrm{I} / 27$ & 7645 \\
\hline 8. & Rokycany-B.Němcové & $\mathrm{MK}$ & 4387 \\
\hline
\end{tabular}




\begin{tabular}{|c|l|c|c|}
\hline 9. & Plzeň-Radčická & $\mathrm{III} / 18050$ & 3769 \\
\hline 10. & Plzeň-Borská & $\mathrm{MK}$ & 12763 \\
\hline 11. & Plzeň-Valcha & $\mathrm{III} / 18043$ & 4278 \\
\hline 12. & Králův Dvůr & $\mathrm{III} / 2363$ & 1807 \\
\hline 13. & Františkovy Lázně & $\mathrm{III} / 21330$ & 5519 \\
\hline 14. & Dobrotice & $\mathrm{III} / 1882$ & 591 \\
\hline 15. & Oldřichov v Hájích & $\mathrm{III} / 2904$ & 3246 \\
\hline 16. & Stráž nad Nisou & $\mathrm{MK}$ & 5104 \\
\hline 17. & Jenišovice & $\mathrm{III} / 28719$ & 907 \\
\hline 18. & Písková Lhota & $\mathrm{II} / 611$ & 4194 \\
\hline 19. & Malá Skalice & $\mathrm{II} / 304$ & 1234 \\
\hline
\end{tabular}

Data from automatic detectors installed on highways and 1st class roads administered by the Roads and Motorways Directorate were used.

Data collection analysis focused on:

- Determination of general relations - division of gaps based on sizes and according to traffic intensity,

- Establishment of typical distribution of distances applicable to the probability of collision of a vehicle with an animal.

\section{DISTRIBUTION OF DISTANCES}

Detectors recorded the value of individual distances between vehicles from 1 to 25 seconds and then from 1 to 20 minutes. For this reason the distribution of distances between vehicles was divided into two steps: (i) analysis with a step ranging from 1 to 25 seconds and (ii) analysis with a step ranging from 1 to 25 minutes. Relative values were used in order to be able to compare individual stations. We can observe this phenomenon on the basis of one particular example.

Example: A station located on Borská road in Plzeň was selected. Traffic intensity $\mathrm{I}=12,763 \mathrm{veh} /$ day, average theoretical intensity per one hour $\mathrm{I}=12,763 / 24=530 \mathrm{veh} / \mathrm{hour}$.

To monitor the situation an interval of $\mathrm{t}=25 \mathrm{~s}$ was selected (intervals up to 25 seconds).

$$
\lambda=\frac{530}{3600} 25=3,69
$$

Figure 2 shows the distribution of measured values of time gaps using theoretical Poisson's division. 


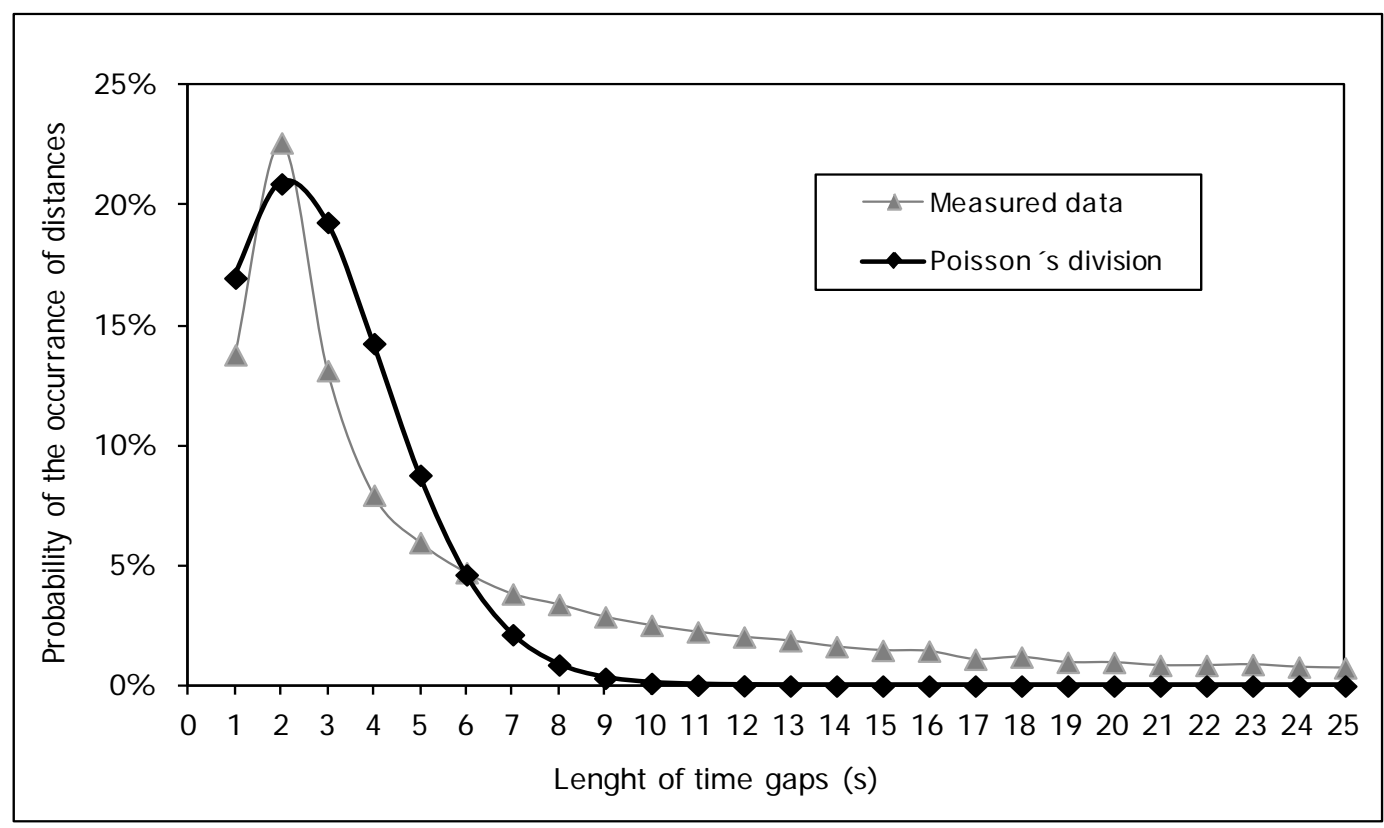

Figure 2: Division of probability of time distances, sample.

The analysis confirmed that the Poisson's division method approximates well the distribution of time gaps between vehicles in traffic flow.

More accurate results were obtained through an analysis of a set of hourly measurements. Here, the influence of the simplification of the conversion of the daily traffic intensity to the hourly intensity was eliminated. The following evaluations took into account hourly traffic intensities - that is, daily variations in traffic intensities were considered.

\section{ROAD BARRIER EFFECT}

The analysis of the time intervals allowed us to evaluate in detail the impact of the traffic intensity on the mortality of animals and the barrier effect of roads at specific locations. When we combined the analysis of time gaps with the estimated speed of animals crossing the relevant road under certain behavioural regimes, we obtained an illustrative idea about the level of the throughput (permeability) of a particular road as well as about the development of this parameter during various times of the day. Analogous analysis may be used in the preparation of detailed measures focusing on reduction of animal mortality and barrier effects such as eco-ducts or road fences.

For the first general approximation we have used a typical distribution of distances for each road category. Average AADT values were determined for each road category (from results provided by the 2005 national traffic census) - see Table 2.

Table 2: Typical AADT values for different road categories.

\begin{tabular}{|l|c|}
\hline Road categories & Average AADT (vehicles / day) \\
\hline Motorway & 23,900 \\
\hline 1st class road & 9,700 \\
\hline 2nd class road & 3,400 \\
\hline 3rd class road & 2,360 \\
\hline Local road & 6,800 \\
\hline
\end{tabular}


These typical or characteristic values determined in this way represent only general simplification when compared with the actual dissipation of AADT values on individual road categories, but they are sufficient for our illustrative purposes.

Using general and derived relations, the existence of time gaps during the day for individual road categories was established (typical AADT value). Daily variations in traffic intensity specified in TP 189 (2012) were used in order to establish the traffic intensity during individual hours of the day.

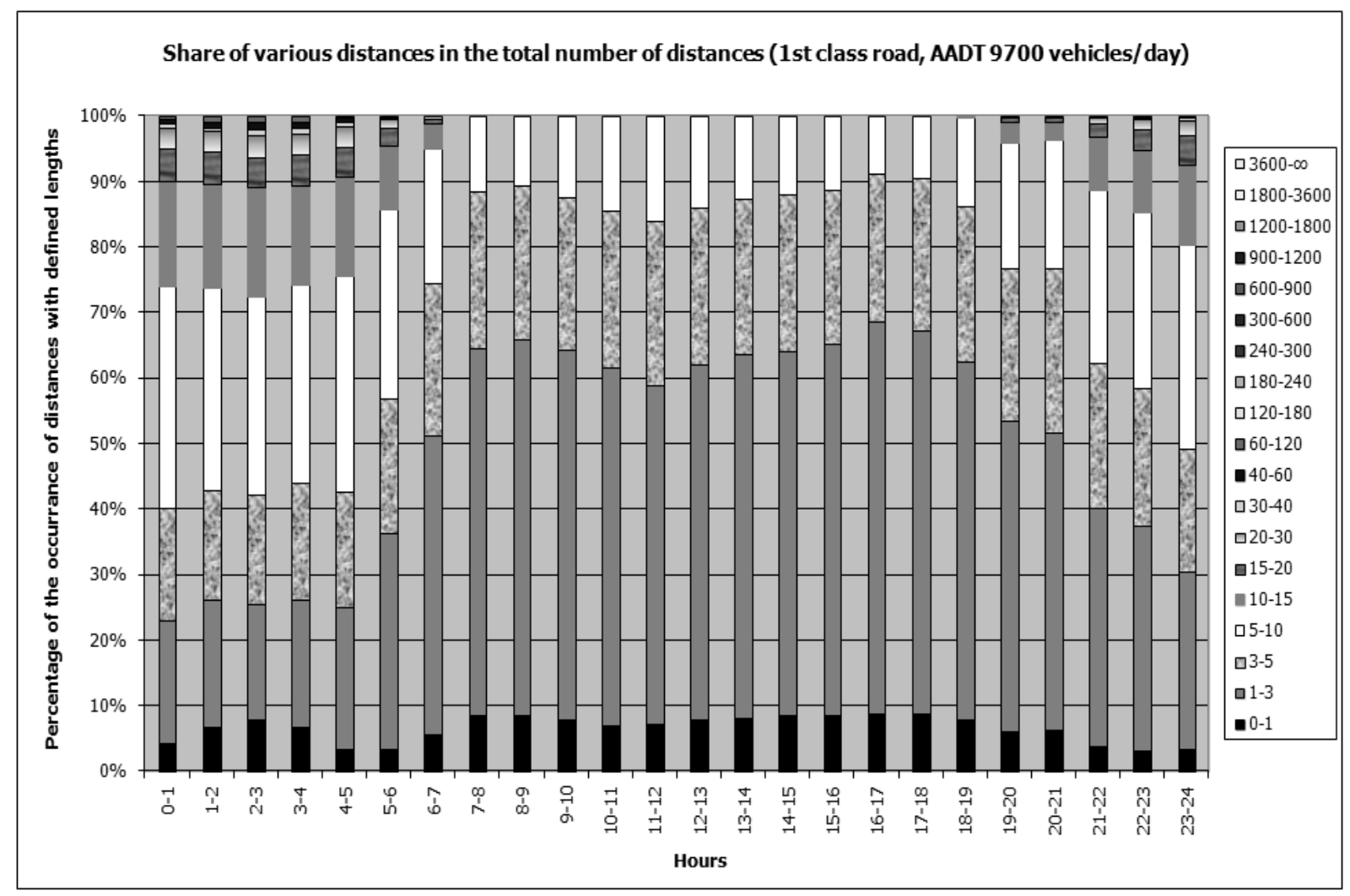

Figure 3: Distribution of time gaps over a regular workday on a typical motorway.

Figure 3 shows the distribution of time gaps between vehicles over a day on a typical motorway.

For the calculation of the probability of vehicle collisions with animals a crucial component is the time which the animal remains on the road. This time is of course dependent on the type of animal, the road parameters (width, center guardrail, etc.), but may vary on the road type even concerning a single species, therefore the value is of statistical nature. The credibility of calculating the probability of occurance depends primarily on how good a model of animal road crossing behavior can be built. In the simplest case, we can consider a uniform rectilinear motion (different speeds for different kinds of animals) in a direction perpendicular to the road.

A road is a barrier for an animal (mechanical - moving vehicles and noise). At low volumes of traffic, for example at night, vehicles distances of tens of seconds to minutes often occur. Such distances allow species to cross easily and the risk of a vehicle striking a deer is small. With an increasing volume of traffic collision risk also increases, but growth stops and the volume of traffic is certain to fall again. During rush hours distances over $5 \mathrm{~s}$ would rarely occur and the road for the animal becomes an insurmountable mechanical and noise barrier with the possibility of migration decreasing to a minimum. 
A typical motorway with AADT 23,900 vehicles / 24 hours between 6:00 am - 10:00 pm does not show time gaps longer than 10 seconds, whereas a 1st class road with a lower AADT value shows time gaps between vehicles up to one minute long. During night time between 10:00 pm - 6:00 am, a motorway shows time gaps between vehicles ranging from 20 to 30 seconds and 1st class roads show time gaps longer than 2 minutes.

Using these diagrams to demonstrate the throughput of the road for animals gives us figures 4 and 5, which demonstrate the throughput of a motorway and 1st class road when an animal crosses the road quickly and directly.

These diagrams demonstrate the share of five model states in terms of road throughput starting with a completely closed road (no throughput) through three, relatively permeable statuses and also a situation with time gaps when the model may be regarded as permeable. Although this is a highly simplified model approach, by comparing both diagrams we see a fundamental difference between the two road types, especially during night time, which is crucial in terms of animal migration. In general, an average highway / motorway is permeable 24 hours a day, whereas an average 1st class road shows relatively high permeability during the night.

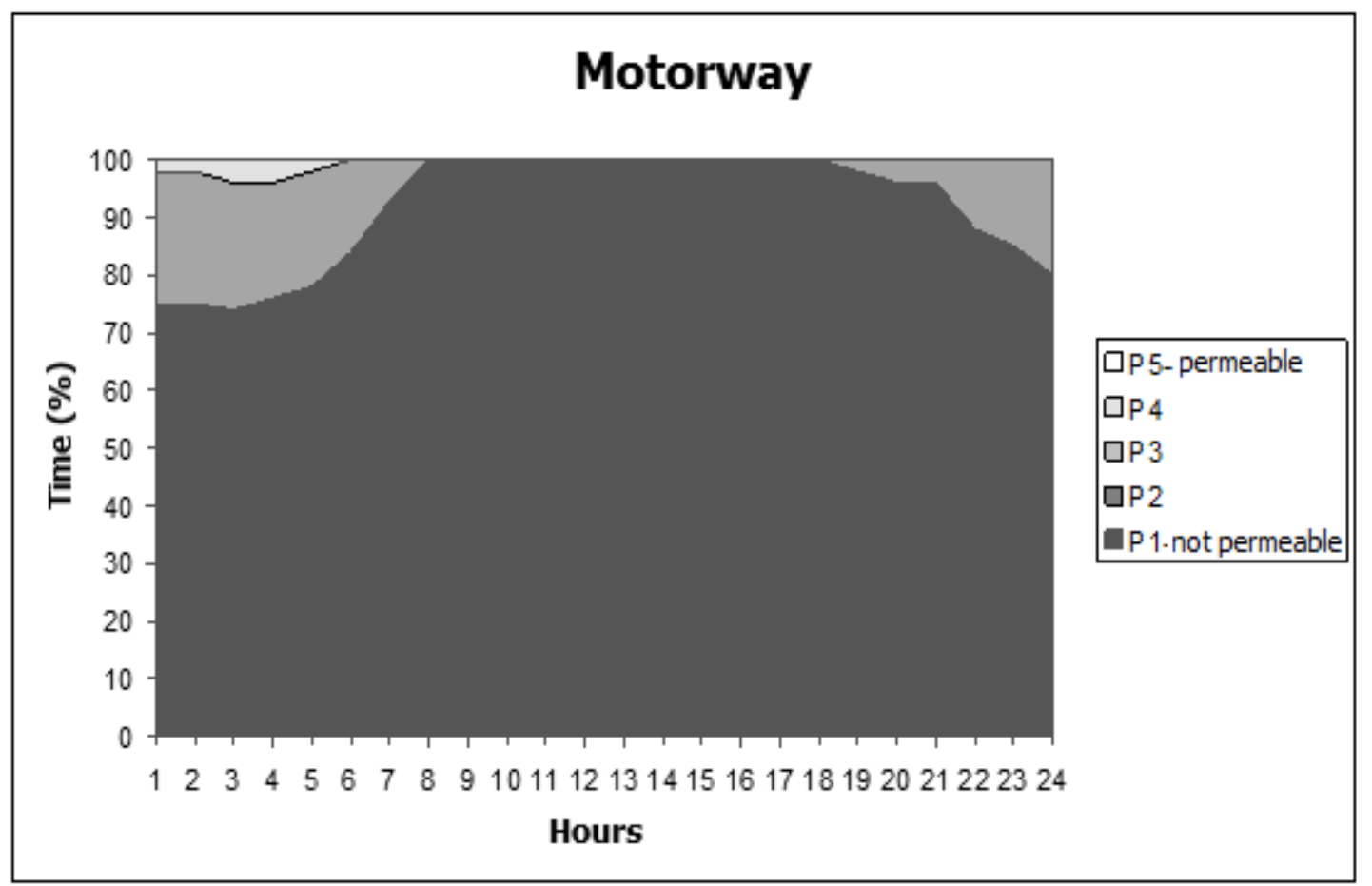

Figure 4: Permeability of a typical motorway during individual hours of a regular workday. 


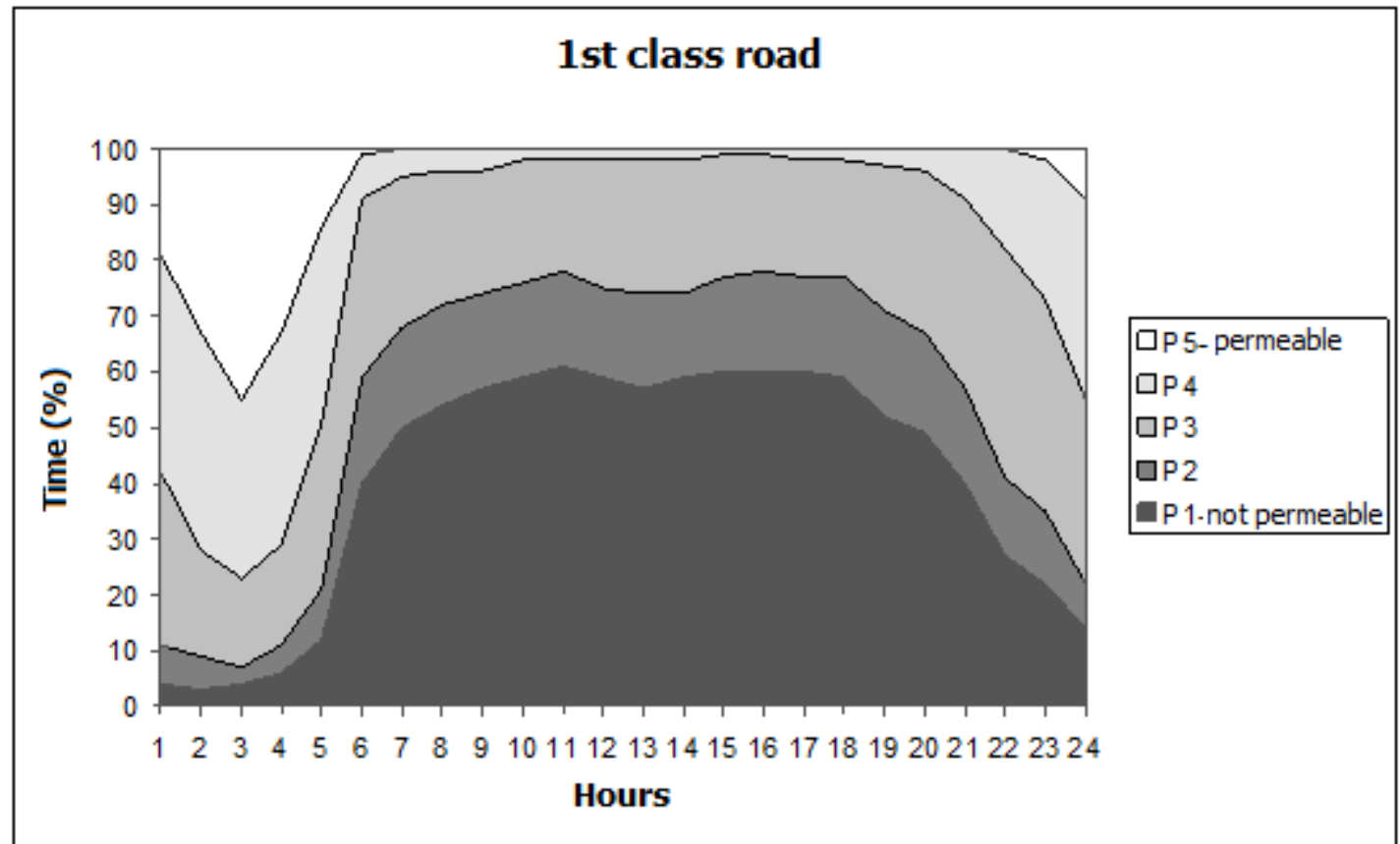

Figure 5: Permeability of a typical 1st class road during individual hours of a regular workday.

2nd and 3rd road classes represent (due to their lower traffic loads) a smaller barrier, especially at night. However, it depends, of course, on the specific traffic intensity at the monitored section of the road.

Local roads (located inside built-up areas, cities and municipalities) do not pose a high danger of collision with animals (not taking into account pets that sometimes wander on these roads rather than cross them). On the other hand, the species "Homo sapiens sapiens" are abundantly present here, but we assume that these species will use the sufficiently large distances between vehicles to properly cross these roads.

\section{CONCLUSION}

Analysis of data obtained from measurements provided by automatic radar enabled us to find general relationships which determine the distribution of time gaps between vehicles in traffic flow. These results were applied (among other applications) to assessments of the impact of traffic on wildlife. These simplified models have shown us the road barrier effect, with certain traffic intensity, on wildlife.

\section{ACKNOWLEDGMENTS}

This article has been published under a set of research projects of the Technology Agency of the Czech Republic No. TA01030107 - Methodology design optimization measures to regulate the movement of animals across the road. 


\section{REFERENCES}

EDIP, 2007. Využití dopravně inženýrských dat a metod pro kvantifikaci vlivů dopravy na životni prostředí [roční zpráva 2007]. Projekt VaV č. 1F55A/065/120. Plzeň: EDIP s.r.o. (in Czech)

Medelská, M. et al., 1991. Dopravné inženierstvo. Bratislava: Alfa. (in Slovak)

Pistulka, B., 1970. Způsoby a výsledky analýzy rozdělení časových intervalů dopravního proudu. In Modernizace a rozvoj silnic, dálnic a místních komunikací. Haviŕrov: ČVT Silniční společnost. (in Czech)

ŘSD, 2006. Výsledky celostátního sčitání dopravy na silniční a dálniční siti ČR v roce 2005 [online]. Praha: Ředitelství silnic a dálnic ČR [cited 2013-07-12]. Retrieved from: http://www.scitani2005.rsd.cz/start.htm (in Czech)

TP 189, 2012. TP 189 - Stanovení intenzit dopravy na pozemních komunikacích. Plzeň: EDIP s.r.o. (in Czech) 